\title{
Del padre rey, al rey niño*
}

\section{From the father as king to the child as king}

\author{
Javier Elzo Imaz \\ Universidad de Deusto \\ javierelzo@telefonica.net
}

Sumario: Introducción. 1. Un importante estudio francés. 2. El estudio en la sociedad americana. 3. El texto italiano de 2013 de Guilio Meotti. 4. Rechazo y superación de legitimación pedófila. 5. La complicada determinación de la edad legal de los menores. 5.1. Sobre una Carta firmada por 60 personalidades francesas y que publicó Le Monde (como remitido) el 26 de enero de 1977. 5.2. La evolución de la mayoría sexual en Francia. 5.3. Las edades legales de los menores en España, en el año 2018. Conclusiones: del padre rey, al niño rey. Referencias bibliográficas

Resumen: El verano de 2018 varias investigaciones en el planeta mostraron la lacerante realidad de la extensión de la pederastia en el clero católico que, en su mayor parte, tuvo lugar muchas décadas atrás. Otras investigaciones concomitantes muestran que, en sectores intelectuales minoritarios pero relevantes, la lectura social de la consideración del niño como sujeto de derechos era muy diferente a la de nuestros tiempos. Entre los años 60 y 70 del siglo pasado hasta nuestros días, se ha vivido un choque entre dos paradigmas: uno menguante, el del padre, y otro creciente, el del niño. Hemos transitado del padre rey al niño rey. Este cambio, también se da en el modelo patriarcal católico, aunque no sea suficiente, en absoluto, para explicar la pederastia clerical.

Palabras clave: pederastia, clero, derechos humanos, cambio cultural, padre, niño.

Abstract: In the summer of 2018 several research initiatives worldwide revealed the lacerating reality of the profusion of child abuse committed by the Catholic clergy, in most cases, decades before. Other contemporary research has shown that, among some reduced —but relevant— intellectual circles,

* Cómo citar: Elzo Imaz, Javier. 2019. "Del padre rey, al rey niño". Deusto Journal of Human Rights, 4: 203-225. http://dx.doi.org/18543/djhr-4-2019pp203-225 
the social interpretation of the child as a subject of rights is now very different from what it used to be. From the 1960s and 70s up to our days, there has been a clash between two different paradigms: One has been waning, which is the one focusing on the father; while the other has waxed, which is the one focused on the child. We have moved from the father as key figure to the child as key figure. This shift has also taken place in the patriarchal model of Catholicism, although, of course, it is not enough to explain the increasing cases of child abuse among the clergy. child.

Keywords: Child abuse, clergy, human rights, cultural change, father, 


\section{Introducción}

El tsunami de la magnitud de la pederastia en el clero católico, en todo el planeta, del que tuvimos un conocimiento intenso y detallado el verano de 2018 (aunque disponíamos de informaciones anteriores, algunas de mucho calado y seriedad) nos dejó a muchos católicos en estado de shock. Paralizados en un primer momento. En mi caso, interrumpí temas que llevaba tiempo trabajando, y temo que alguno de ellos, dada mi edad y la acumulación de requerimientos, para siempre. Así, con fecha de 3 de octubre de 2018 escribí en mi blog un primer texto de reflexión sobre la cuestión de la pederastia en el clero católico, que titulé "La pederastia en el clero: breves apuntes para una lectura sociológica", advirtiendo en la cabecera que era un texto provisional². Envié el texto a un centenar de amigos, así como a algunos portales de ámbito religioso y recibí algunas sugerencias de mejora. Con ellas y con más información, en noviembre de 2018 intervine en la Universidad de Granada con una conferencia bajo el titular: "Abusos de menores y credibilidad de la Iglesia", complemento del texto anterior ${ }^{3}$. Y después publiqué un texto, aún más abreviado sobre el mismo tema en el que, obviamente, recogía algunos aspectos de los dos textos anteriores, actualizados y completados con más lecturas que se iban produciendo ininterrumpidamente aquellos meses (Elzo 2019).

Más adelante, un amigo teólogo en el Antonianum de Roma me invita a participar en un libro colectivo, con el título: Sexual Abuses in the Catholic Church and Covering Them Up: ¿What Went Wrong? ${ }^{4}$. Para ese proyecto redacto otro texto que contiene, respecto de los anteriores, dos novedosas aportaciones de gran interés, particularmente para el presente texto que elaboro para la Revista Deusto de Derechos Humanos.

En mis archivos personales, había guardado hace años un trabajo francés que refería la lectura que, a finales del siglo pasado, hacía una parte importante de la intelectualidad francesa defendiendo la práctica de la pedofilia, con una determinada concepción del menor, incluso del niño (Verdrager 2013). Al abordar en el último cuatrimestre del año

2 En el texto señalo algunas de las informaciones más relevantes publicadas hasta ese momento.

3 Estos textos pueden consultarse en el enlace: https://javierelzo.blogspot. com/2018/11/abusos-de-menores-y-credibilidad-de-la.html

4 Libro que será editado por él mismo y por un conocido sociólogo americano en una editorial de EEUU. No desvelo sus nombres ni los de los colegas participantes en el proyecto (que vienen de medio mundo), pues está aún sin terminar. 
2018 la cuestión de la pederastia en el clero católico, recordé aquel trabajo, lo estudié con detenimiento y lo introduje ya en mi trabajo arriba reseñado de octubre de 2018. Antes hice mención del mismo en un par de textos breves que envié a algún portal religioso, provocando una dura reacción de algunas personas que me acusaban de querer blanquear o justificar la pederastia del clero, lo que obviamente estaba lejos de mis intenciones. Esto me llevó a ser muy cuidadoso en la presentación de mis textos, empezando por el ya reiterado del 3 de octubre.

Mas, he aquí que, uno de mis lectores, me advierte que a finales del siglo pasado, en los EE.UU, en parte por el "ruido" mediático que ocasionó la acusación de pederastia del cineasta Roman Polanski (que todavía hoy no se atreve a pisar los EE.UU.) una investigadora, Mary Eberstadt (2009), publica unos textos en los que, como en Francia, refiere cómo una parte de cierta intelectualidad norteamericana justificaba también la pederastia, a condición de que fuera realiza con chicos, con varones, y no con chicas.

Más adelante, en abril de 2019, el Papa emérito Benedicto XVI, escribe un texto para una revista alemana para el clero, donde aborda el tema de la pederastia en el clero, refiriéndose a determinados pronunciamientos y prácticas de pedofilia justificativas que tuvieron lugar, no solamente en su país de origen, Alemania, también a finales del siglo pasado ${ }^{5}$. El Papa Benedicto hace referencia, entre otros, a mayo del 68. Estamos ante un extraño y singular texto del Papa emérito. Extraño, pues en siete años de emérito nunca se había pronunciado con tanta extensión sobre un tema tan candente en la Iglesia y en un discurso que difiere del Papa Francisco. Singular por la escasa calidad intrínseca del texto, inhabitual en un hombre que nos ha legado textos de un rigor y profundidad excepcionales. Incluso cuando se pueda ser crítico con alguno de sus pronunciamientos. El texto que se filtró (¿por quién?) al New York Post, que lo publicó el 10 de abril, se parece más a un borrador, dada su escasa calidad redaccional. De ahí que no diremos nada más sobre este texto en las páginas que siguen.

Sin embargo, la filtración del texto del Papa emérito, con su referencia a mayo del 68, hizo que emergiera en el debate público el texto del periodista Giulio Meotti (2013), quien había abordado años atrás la misma cuestión de Pierre Verdrager y de Mary Eberstadt, sobre la justificación de la práctica de la pedofilia en Alemania y Austria,

5 Una traducción al castellano, parece que mejor cotejada que la primera que se dio a conocer, puede consultarse en https://www.aciprensa.com/noticias/el-diagnostico-debenedicto-xvi-sobre-la-iglesia-y-los-abusos-sexuales-35201 
con referencias a Francia que coinciden con las de Verdrager. Nos detendremos, aun brevemente, en ese texto, básicamente para mostrar la concordancia en determinada visión del menor en el tema de la pederastia en general.

En efecto, las páginas que siguen no pretenden volver a la cuestión de la pederastia en el clero. Nuestro objetivo para este artículo pretende, utilizando la información recogida para estudiar la pederastia en el clero católico, analizar cómo era visto el papel del menor, básica, pero no exclusivamente, en la cuestión de las relaciones sexuales, qué valores se pretendían defender, hasta qué punto el menor era sujeto de derecho y de qué derechos, su relación con los derechos humanos de los adultos y los suyos propios, etc. Mi planteamiento no será el de un jurista. Tampoco el de un moralista. Será el de un sociólogo que se preguntará por qué se ha modificado tanto la ley en relación al menor y su edad legal; por qué, una parte, aunque en absoluto mayoritaria, de la sociedad francesa, americana y centro europea ha "bendecido" la relación sexual de adultos con menores para considerarla, en la actualidad, como una de las mayores abominaciones posibles. Lo haremos presentando los trabajos ya citados de Verdrager, de Eberstadt y de Meotti, antes de permitirnos unas consideraciones sociológicas, ya avanzado el texto.

\section{Un importante estudio francés}

Reflexionamos, a continuación, en base al trabajo de Pierre Verdrager, ya citado anteriormente. El libro se publicó el año 2013, y afloró de nuevo en la literatura francesa el verano de 2018, con motivo de la pederastia en el clero. Me impactó su contenido. Mostraba cómo la pedofilia fue justificada y qué razones esgrimían algunas élites francesas en los años 70 y parte de los 80 del siglo pasado y cómo en la actualidad, por el contrario, la pedofilia es considerada como una de las peores lacras que se pueda imaginar. Su lectura me dejó anonadado. Entre otras razones porque aquellos años yo los viví en Paris y Lovaina y, aunque de algunos autores (Michel Foucault) y personajes célebres (Gandhi y Daniel Cohn-Bendit) ya se hablada que habían mantenido relaciones con menores, no recordaba que el tema tuviera el peso que le concede el libro.

Creo que este libro hay que leerlo. No resuelve nada, no relativiza nada, pero contextualiza, y mucho. Insisto en que no relativiza nada del tema de la pederastia clerical, pues el estamento clerical estaba bastante lejos del horizonte intelectual de los que justificaban la 
pedofilia, básicamente del mundo de la "izquierda radical" en el mundo de la farándula, por decirlo en el lenguaje de hoy. Pero, para el tema de este artículo, el libro es muy importante pues muestra el papel del niño y del menor en la justicia de su tiempo y en los sistemas de valores imperantes, en lo que concierne a los derechos del niño y del menor.

El autor señala cómo, en los primeros años posteriores a mayo del 68 , en determinados medios intelectuales franceses entienden que el niño debe ser considerado como un adulto, también en el terreno sexual. Pensar lo contrario supondría mantener la represión y el dominio de los adultos en general hacia los niños, y más en particular, de los padres, en el seno de la familia. No hay que olvidar que en aquellos años y hasta bien avanzada la década de los 80, la familia como institución sufrió no pocos embates, "reputada como el lugar privilegiado de la dominación" (Verdrager 2013, 49), hasta el punto de defender "la muerte de la familia", título de un renombrado libro de David Cooper $(1986)^{6}$, familia que era vista como el "gulag" de los niños.

Los padres podrían ser vistos como asesinos potenciales. Verdrager $(2013,52)$, citando un trabajo de Tony Duvert (1974, 108), escribe, a continuación, que "en Alemania del Oeste se dan cada año nueve mil niños asesinados por sus propios padres. Unas cifras equivalentes se han encontrado en otros países de Europa o de EE.UU. (...) no son muertes por accidentes de tráfico sino muertes producidas por malos tratos llevados a cabo por papá y mamá sobre sus tiernos hijos". Y de ahí, avanza Verdaguer, que "el pedófilo, pensaban algunos, representaba una oportunidad para los niños: era quien podría rescatarlo de las cadenas familiares, incluso salvarle la vida (...) pues ellos, al menos, amaban a los niños, que es lo que quiere decir precisamente el término de pedófilo". Es evidente que nos encontramos en la antítesis del pensamiento actual cuando los actos pedófilos se nos aparecen como los más horribles que un adulto pueda cometer. Pero, es preciso decir, desde ya, que el planteamiento que describe y señala Verdaguer, de rechazo de la familia tradicional aliado a la bienvenida acción pedófila no era, en absoluto, aceptada por la totalidad ni por la mayoría de la población, y de hecho fue criticada, también intelectualmente, y al final del largo proceso intelectual, extremadamente minorizada.

6 Hay varias ediciones en castellano. El original en inglés es de 1971 y se ha reditado muchas veces. Recuerdo vivamente su influencia en España durante la transición. 
Lo que no cabe decir de la familia como tal que, todavía en la actualidad, sobre todo la familia tradicional, sigue siendo muy cuestionada en muchos ámbitos. Es la defensa de la pedofilia y su correlación con la crítica a la familia tradicional la que, tras unos diez años, más o menos, de discusiones y controversias quedó como una opción extremadamente minorizada y prácticamente desaparecida de la literatura publicada.

Pero no nos adelantemos. Además del argumento de los malos tratos familiares para justificar la pedofilia, hubo otros argumentos en su favor. Uno, extremadamente importante y que sirvió para tal justificación responde a una determinada lectura del psicoanálisis. Escribe Verdrager: "el psicoanálisis fue una referencia fundamental en la justificación científica de la pedofilia, no solamente porque había teorizado (desde antes de Freud) la presencia de la sexualidad en los niños, sino igualmente porque había previsto la crítica o el rechazo de esta teoría descalificándola como 'resistencia'. Réné Schérer (1982) consideraba que se debía a Freud la idea de que los niños conformaban el primer objeto de deseo de los adultos. E, incluso, si Freud propugnaba la represión de tal pulsión en nombre de la prohibición del arcaico incesto, lo que Schérer lamentaba profundamente, había que admitir que se había llevado a cabo un gran descubrimiento". En consecuencia, "si la sociedad rechazaba la pedofilia, era en virtud de que 'resistía' a la sexualidad infantil y estaba dominada por los tabúes" (Verdrager 2013, 53-54).

Ciertamente no todos los psicoanalistas de entonces apoyaban tal punto de vista. Verdrager cita, a título de ejemplo, el caso de Françoise Dolto, católica, quien rechazaba la pedofilia. Sin embargo, añade Verdrager, que Dolto firmó una petición dirigida al Parlamento en la que se solicitaba la despenalización de las relaciones sexuales consentidas entre adultos y menores de 15 años, así como una revisión del Código Penal en ese sentido. Volveremos más adelante a la cuestión del consentimiento infantil y a la edad legal para tal consentimiento. Pero, y antes de señalar otros ámbitos científicos de legitimación de la pedofilia, vaya, a título de anécdota y más que de anécdota, una afirmación de Michel Foucault de aquellos años.

En el prólogo al libro de Verdrager $(2013,11)$, François de Singly reseña una idea de Michel Foucault, una de las figuras centrales de la intelectualidad francesa de aquellas años, quien afirmó, en un debate coloquio, que "asumir que, mientras un niño sea un niño, no podemos explicar qué supone la infancia, que mientras él sea un niño, no pueda consentir, estamos ante dos abusos que son intolerables, 
inaceptables"7. Nótese la utilización del término "abuso" que, en la década de los años 70 y parte de los 80 del siglo pasado, es entendido como un abuso de los mayores al no reconocer "los derechos" de los niños, como tales niños, incluso en su vida sexual con adultos, a diferencia de cómo entendemos nosotros en la actualidad el término "abuso" para significar que los adultos utilizan a los niños para satisfacer sus deseos sexuales ${ }^{8}$.

Apuntemos, además del argumento psicoanalítico, el argumento antropológico de constatar que en otras culturas la pedofilia no solamente era admitida sino bienvenida. Así, por ejemplo, en algunas culturas se sostenía que mediante la sodomía generalizada el menor sodomizado adquiría la fuerza del adulto. Parece que esta práctica era habitual entre algunos monjes budistas y los Samuráis de Japón (Verdrager 2013, 58 y ss). El argumento antropológico de fondo esgrimido venía a decir que las relaciones sexuales entre adultos y niños existían en otras sociedades, luego el actual rechazo a las mismas era algo contingente y arbitrario, y que podría cambiar al albur de los cambios culturales. Es el relativismo cultural que es utilizado a menudo en las ciencias sociales, aunque un análisis serio exige mostrar cuál es el razonamiento de base (y las fuerzas sociales) que lo sostienen. Cuestión clave a la que hemos de volver más adelante.

Pero, siguiendo con la apelación a las ciencias humanas o sociales para justificar la pedofilia, detengámonos, brevemente, en el argumento histórico, en relación a la antigua Grecia, mil veces utilizado. Veámoslo de la mano de Gérard Bach (1984), "la mejor referencia, según Verdrager, para analizar la ligazón entre la causa pedófila y las ciencias sociales". Así lo hace en un análisis sociohistórico de lo que sucedía en la Grecia Antigua: "lo que parece que más ha cambiado desde la Grecia Antigua es la relación con los niños. Si el mundo griego de antes de nuestra era valorizaba la relación de un hombre adulto con un muchacho joven, reside en que entonces se consideraba tal relación sexual más igualitaria que la relación con una mujer. La mujer en la sociedad griega es siempre una subordinada; el muchacho joven, al contrario, está llamado a devenir un hombre con

7 Para contextualizar la afirmación de Foucault, véase: http://1libertaire.free.fr/ MFoucault317.html. Este texto es un la transcripción de un debate público en la radio France Culture, el 04/ 04/1978, entre un abogado, un periodista de Gai Pied (periódico pro homosexual), un filósofo defensor de la homosexualidad y Michel Foucault. No tiene desperdicio para entender qué cuestiones se planteaban en aquellos años en Francia sobre este tema. Es también un ejemplo de lo que es una radio de calidad que aborda con seriedad temas de importancia, incluso escabrosos.

8 Un ejemplo lo tenemos en el título del libro de Javier Urra (2007). 
todo su poder, y esta situación le marca desde su infancia. La relación con un hombre adulto es para él, un rito iniciático que le resulta socialmente útil. En la actualidad, si la pedofilia está prohibida en la mayor parte de las sociedades occidentales, es porque se considera que el niño no es capaz de discernimiento en sus elecciones, a diferencia de los adultos. Se trata, concluye Bach, de una ficción" (Verdrager 2013, 55-56).

Es imposible no ver en este razonamiento el peso cultural, los sistemas de valores imperantes, en las diferentes sociedades, no solamente a la hora de enjuiciar las relaciones sexuales de adultos y menores, sino algo más radical, en el sentido de que va a la raíz de la priorización y legitimación de los modelos masculinos y femeninos, que vamos a encontrar en EE.UU. a finales de los años 90 del siglo pasado, como mostraremos más adelante. Más allá de los derechos del menor, objetivo central de estas páginas, es preciso señalar que, tales derechos, como prioridades vitales, son diferentemente valorados a tenor del sexo del menor, haciendo así del sexo una cuestión de género.

\section{El estudio en la sociedad americana}

El mes de diciembre del año 2009 la investigadora Mary Eberstadt publicó un artículo, titulado "How Pedophilia Lost Its Cool" en la revista First Things, en el que referencia también otros trabajos suyos de los años 90 del siglo pasado, así como otras publicaciones científicas americanas, incluso anteriores a los años 90. La autora muestra cómo entre los años 1970 a 1990, en ciertos ámbitos culturales, que etiqueta de refinados, no sólo no se escandalizaban ante los abusos a menores, sino que, en algunos supuestos, los favorecía y aprobaba. Ciertamente este dato no exculpa los crímenes de clérigos en esos años, pero ayuda a contextualizar y sobre todo a entender, que no justificar, la leve y tardía reacción de las autoridades eclesiásticas.

A continuación, vamos a mostrar lo esencial del trabajo de la investigadora americana, utilizando sus propias palabras. Escribe Mary Eberstadt (2009): "No fue hace mucho tiempo que algunas personas ilustradas adoptaron una visión considerablemente más relajada de la cuestión del sexo con los menores (youngsters), y no temían decirlo. Desde la década de 1970 hasta la década de 1990, se lanzaron varios globos sonda que casi nadie en Estados Unidos se atrevería a lanzar ahora. Algunas personas, incluidos novelistas célebres, preguntaron directamente si el sexo con menores de edad valdría una o dos 
alegrías (might be worth a cheer or two). Otras voces sofisticadas se preguntaban en voz alta si el 'sexo intergeneracional' era realmente tan malo como se decía, al menos en lo que respecta a los chicos (boys). Otros afirmaron lo que podría llamarse 'anti-anti-pedofilia'. Esta fue la noción frecuentemente expresada de que el abuso sexual de niños, aunque malo, había dado lugar a algo que también estaba mal: una especie de histeria nacional".

Y referencia la autora dos ensayos suyos escritos en los años 1996 y 2001, en Weekly Standard, en los que, con profusión de largas citas, mostraba cómo, a decir de mucha gente, "la moralidad tanto de la pedofilia (atracción sexual hacia los niños) como de la efebofilia (atracción sexual hacia los adolescentes) estaba progresando de manera lenta pero constante en ambientes sofisticados de la sociedad". Pero no solamente entre la gente sencilla sin mayores conocimientos sino también en ámbitos académicos de primer nivel. Así, la autora escribe como en el año 1998 se publicó un notable estudio, bajo el patrocinio de la American Psychological Association, en el que tres investigadores se mostraron en desacuerdo con "la creencia común de que el abuso sexual infantil causa un daño intenso, sin importar el género" (Rind, Tromovitch y Bauserman 1998). Los autores criticaron aún más el uso de términos convencionales como víctima y perpetrador, y recomendaron que "un encuentro voluntario con reacciones positivas" se etiquetara como "simplemente sexo entre adultos y niños". En buena medida, también compararon el sexo consensual entre adultos y niños con los comportamientos de "masturbación, homosexualidad, felación, cunnilingus y promiscuidad sexual" que en la APA alguna vez consideraron patológicos, pero ya no. El texto implicaba claramente que "el sexo 'adulto-niño' algún día se volvería tan normalizado en los círculos terapéuticos como lo habían hecho esos predecesores".

Retengamos dos ideas mayores de los textos de Mary Eberstadt. Por un lado, cómo en determinados ámbitos sociales, la práctica, el paso al acto, tanto de la pederastia como de la efebofilia, no solamente no eran condenados, sino que eran considerados como algo natural e incluso en vías de normalización futura, una vez superadas ciertas barreras ideológicas de signo anti-pederastia. Por otra parte, nótese la diferencia que se realizaba cuando la relación sexual entre adultos y menores se llevaba a cabo con chicos, que se legitimaba, a diferencia de la condena que se mantenía cuando lo era con chicas adolescentes, o con niñas. $Y$ se refiere concretamente al caso del cineasta Roman Polanski, cuya extradición por la violación de una niña de 13 años en 1977 se solicitó durante muchos años, lo que quizá no habría sucedido, 
o al menos alcanzado el volumen que alcanzó, si se hubiera tratado de un niño, sostiene Eberstadt (2009).

Apuntemos también, para el tema que nos ocupa en estas páginas, la relación que observa Eberstadt entre la pederastia en el clero y la vuelta a la condena de la pederastia, si no en el conjunto de la sociedad americana, sí en la opinión publicada. Escribe Eberstadt (2009) al inicio que "La razón por la que importa tanto el crimen monstruoso de la pedofilia (en el clero) es simple: en una era cada vez más secular, es uno de los pocos tabúes sobre los cuales las personas, tanto religiosas como no religiosas, pueden estar de acuerdo. Sigue siendo un marcador de lo correcto y lo incorrecto en un mundo donde se han borrado otros marcadores". Y, ya concluyendo su texto, podemos leer esto: "demos la bienvenida a las buenas noticias cada vez que podamos obtenerlas. El furor público por la violación de Roman Polanski de una niña de trece años hace muchos años ha revelado con fuerza que, en la mayor parte de los Estados Unidos, el conocimiento ambulante de ayer sobre el sexo con menores ha sido expulsado de la corriente principal y ha sido obligado a volver a la clandestinidad. Es un consenso que no existía con esa fuerza hace una década, y los escándalos de los sacerdotes son en gran parte responsables de ello".

Concluyamos también nosotros esta breve recensión de los trabajos de la investigadora americana subrayando el impacto de la pederastia en el clero católico, coincidiendo con los debates en torno a la demanda de extradición de Polanski (refugiado en Suiza), a la hora de volver a rechazar las relaciones sexuales de adultos con menores, que décadas atrás, entre 1970 y 1990, habían sido no solamente toleradas, sino incluso positivamente valoradas y fomentadas en determinados ámbitos socio-culturales progresistas, cuando se trataba de relaciones entre hombres y niños o chicos adolescentes.

\section{El texto italiano de $\mathbf{2 0 1 3}$ de Guilio Meotti}

Ya hemos mostrado más arriba cómo, tras la filtración de unas notas del Papa emérito Benedicto XVI, alguna prensa conservadora de Iglesia sacó a relucir una información del periodista Giulio Meotti, publicada en la prensa italiana que, sin embargo, en el momento de su publicación, pasó sin pena ni gloria y solamente salto en los medios de comunicación por la filtración de las notas de Benedicto XVI, en marzo de 2019. Sin embargo, para el objetivo de estas páginas, el texto de Meotti (2013) tiene su importancia porque muestra que, lo que hemos 
sabido de la corriente pro-pederasta en Francia y en EE.UU. también se dio en centro Europa, mostrando el autor referencias concretas en Alemania, Austria y Holanda. Además, subraya la situación en Francia, confirmando, si falta hacía, la información que nos suministra Verdrager y que arriba hemos mostrado. Veámoslo sucintamente.

El autor hace referencia a un informe publicado en aquellos días en el semanario Der Spiegel, donde se anunciaba que en los años 80 del siglo anterior numerosas asociaciones de izquierda y de intelectuales que luchaban por los derechos de los homosexuales formaron una especie de alianza con los militantes de la pedofilia.

Más en concreto referencia cómo, en julio de 1981, la revista gay Rosa Flieder entrevistó a Olaf Stüben, que entonces se destacaba por su declarado apoyo a la pedofilia. En la entrevista, Stüben reivindicaba abiertamente el derecho a reconocer la pedofilia como "algo sano y moralmente aceptable". Afirmaba que la inocencia adolescente que debía defender a los muchachos ante el sexo era solo "una invención de los burgueses del primer capitalismo".

El artículo de Der Spiegel explica cómo esa entrevista no fue un caso aislado. En los años setenta e incluso en los ochenta, muchas revistas de izquierda sostenían y promovían el sexo con niños. La revista Don, por ejemplo, publicó cinco informes favorables con el título: "No somos estupradores de niños".

Entre los numerosos artículos que señala Giulio Meotti, retenemos aquí unos pocos más, por la significación de sus autores o de los centros a ellos asociados.

Como resultado de una investigación parlamentaria se supo que el Psychology Institute de la Free University de Berlín había apoyado al centro Libertad Roja e incluso la ministra de justicia alemana el año 2013, la liberal Sabine Leutheusser-Schnarrenberger formó parte de la directiva de la Humanistische Union, cuando esta organización progresista se batía para liberalizar todos los actos sexuales "consensuados", incluso con menores.

Asimismo, señala Meotti que se abrieron asilos en los que se sostenía que los niños tendrían derecho a vivir la sexualidad. Refiere en concreto el número 17 de la revista Kursbuch, publicado en 1969 bajo la dirección de Hans Magnus Enzensberger, que contenía un artículo titulado "Educar a los niños en la común", en referencia a la casa "común" socialista de Giesebrechtstrasse en Berlín, a la que fueron a vivir tres mujeres, cuatro hombres y dos niños. Además de tener el dinero en cuentas comunes y de no tener puertas en los baños para favorecer la "comunión", la casa preveía experiencias sexuales con los menores. 
También en una prestigiosa escuela ligada a la Unesco hubo abusos sexuales entre los años setenta y ochenta. Se trata de la Odenwald de Heppenheim, conocida por su método pedagógico basado en el "libre desarrollo de cada alumno". El instituto tenía entre sus alumnos al mismo Daniel Cohn-Bendit, que asistió allí entre 1958 y 1965, a uno de los hijos del expresidente de la República Federal Alemana, Richard von Weizsäcker, Andreas, al hijo de Thomas Mann, Klaus, y a Wolfgang Porsche, hoy a la cabeza de la famosa casa automovilística de la familia del mismo nombre.

Cohn-Bendit publicaría luego Gran Bazar, ensayo dedicado a su experiencia en la escuela. En línea con algunas ideas promovidas en el ámbito de los movimientos de contestación de los años sesenta y setenta, algunos pasajes del libro se refieren al "despertar de la sexualidad de los niños" entre uno y seis años, y asume además la posibilidad de relaciones físicas ambiguas.

Cohn-Bendit siempre se ha defendido diciendo que sus afirmaciones eran una "provocación intolerable", pero que deben considerarse en el contexto de los años setenta cuando apuntaban a "chocar con los burgueses". Se trataba del liceo de las élites del 68 donde se teorizaba que "enseñar es equivocado" y que "no hay diferencia entre adultos y niños". Un instituto en el que se verificaron, "al menos desde 1971", abusos "que superan nuestra capacidad de imaginación" (palabras de la directora del Instituto, Margarita Kaufmann, el año 2013).

La controversia ético jurídica que refiere Meotti entre el maestro del pensamiento del anti humanismo, Michel Foucault, y el analista del lenguaje totalitario J. P. Faye, merece ser trasladado casi "in extenso". Michel Foucault, escribe Meotti (2013), sostenía que el niño es "un seductor" que busca el contacto sexual con el adulto. En una entrevista aparecida en Change en 1977 y republicada en Dits et écrits (Gallimard), J. P. Faye y otros le hacen algunas preguntas al célebre filósofo: "Una niña de ocho años - dice Faye- es estuprada por un joven agricultor en un granero. Luego vuelve a casa y su padre hace de médico y cardiólogo (...). Ve volver a casa a la hija que no abre más la boca. Se queda completamente muda varios días, tiene fiebre... En pocos días, sin embargo, verifica que está herida físicamente. El padre cura la laceración, sutura la herida. Médico y seguidor de Wilhelm Reich, no hace la denuncia. Se limita a hablar con el agricultor, antes de que se vaya. No toma ninguna acción judicial pero el relato prosigue con la descripción de una enorme dificultad física de la niña a nivel de la sexualidad años más adelante. Algo que es verificable solo casi diez años después. Es muy difícil pensar en algo a nivel jurídico en este caso. No es fácil a nivel de la psique, aunque parece más sencillo a nivel del cuerpo". 
La réplica de Foucault: "Todo el problema en el caso de las niñas y también de los niños - porque, legalmente el estupro en el caso de los niños no existe- es el problema del niño que es seducido o que comienza a seducirte. ¿Se puede hacer de legislador ante la siguiente propuesta? ¿Con un niño que consiente, con un niño que no rechaza, se puede tener algún tipo de relación sin que la cosa ingrese en el ámbito legal? El problema tiene que ver con los niños. Hay niños que a los diez años se lanzan sobre un adulto ¿y entonces? Hay niños que consienten".

Responde Faye: "También los niños entre ellos, pero en esto se cierra los ojos. Sin embargo, cuando un adulto entra en el juego ya no hay más igualdad ni equilibrio entre los descubrimientos y las responsabilidades. Hay una desigualdad... difícil de definir". Cierra Foucault: "Estaría tentado a decir que, si el niño no rechaza, entonces no hay razón alguna para sancionar el hecho, cualquiera que sea. Además, existe también el caso de un adulto que está en relación de autoridad respecto al niño, ya sea como padre, como tutor o como profesor o médico. También aquí estaría tentado a decir: no es cierto que de un niño se puede obtener aquello que no quiere realmente a través del efecto de autoridad".

Como ha explicado la historiadora Anne-Claude AmbroiseRendu, el discurso según el cual "los niños tienen derecho a la sexualidad" encontró un nicho "a la sombra de los movimientos alternativos de la antipsiquiatría y de la militancia homosexual". Ese fue el caso del escritor francés Tony Duvert (1974), autor del Buen sexo ilustrado, ya referenciado por Verdrager, una especie de "manifiesto pedófilo" que reclamaba el derecho de los niños a su propia liberación sexual.

El debate entre Faye y Foucault sobre las imbricaciones éticojurídicas de la relación sexual entre menores y adultos nos da paso para abordar la última parte de este texto: cómo, al abordar la relación disimétrica entre niños y adultos y trasladarla al ámbito de la ética y del derecho, la legitimación de la pederastia desaparece de los textos publicados.

\section{Rechazo y superación de legitimación pedófila}

La razón principal que provocó el rechazo de la legitimación pedófila, rechazo que acabó imponiéndose no solamente en la sociedad francesa, y en un espacio breve de tiempo, proviene de la evolución en la lectura que se hizo de la condición infantil. Un niño 
está dotado de una identidad específica, no es, sin más, un adulto en potencia, es un sujeto de derechos como tal niño que es, con sus singularidades propias, que impiden una mera similitud a los derechos de los adultos. Dicho de otra forma, el niño mantiene los mismos derechos que un adulto en tanto que es tan persona como el adulto, pero, dada su fragilidad de niño, exige protección. Un niño, en tanto que niño, dada su talla y dado que se encuentra en un proceso natural de madurez (psicológica, intelectual, volitiva, etc.) no tiene las mismas posibilidades de un adulto, tanto para adoptar decisiones como para defenderse de posibles agresiones o abusos de todo orden. Esto hace que, frente al niño, a los derechos del niño -y del menor cabe decir, aunque la cuestión de la edad en la que una persona deja de ser menor sea cuestión debatida, como veremos más adelante- haya dos dimensiones que no siempre resultará fácil articular: sus derechos como persona, luego respeto, con las limitaciones que se considere y justifique, a su libre albedrío, y su derecho a la protección, protección específica en tanto que niño y menor.

La relación niño-adulto no es una relación simétrica, sino claramente asimétrica en la que el adulto tiene ascendiente neto sobre el niño. Que sea en el seno de la familia, de la escuela, del ocio y tiempo libre, del trabajo, etc., luego también en las relaciones sexuales. Cuando un niño o un menor mantiene relaciones sexuales con un adulto, incluso supuestamente consentidas, no estamos ante una relación simétrica entre dos personas adultas, sino claramente asimétricas. Particularmente si el adulto supera en bastantes años al menor, y no digamos si tiene algún tipo de ascendiente sobre el niño o menor, que sea de tipo familiar, escolar, ocio, laboral, etc. Obviamente aquí se inscribe, también, la particular gravedad de la relación sexual entre un sacerdote o religioso con el niño o menor, a quienes conoce en el marco de su acción pastoral.

Va a ser la asunción de esta doble dimensión del niño y del menor, como sujeto de derechos y necesitado de protección, uno de los factores clave para que la tesis filo-pedófila sea definitivamente vencida, en Francia, y no solamente en Francia, en la dialéctica de los años 80. No será el único factor. En la explicación de fenómenos sociales es prácticamente imposible determinar, con exactitud, el peso de un determinado factor o variable, como sucede en las ciencias experimentables en laboratorio. En Ciencias Sociales siempre hemos de hablar de multi-factores o multi-variables, siendo extremadamente difícil controlar, con rigor, el peso de este o aquel factor en su correlación con el fenómeno en estudio, en comparación con otros factores que concurren en el fenómeno a estudiar. 
En el tema que nos ocupa habría que adentrase, por ejemplo, en la discusión sobre las diferentes lecturas que se hacían en la relación entre la homosexualidad y la pedofilia, que de una equiparación total ("la homosexualidad conduce a la pedofilia" sostenían no pocos) se ha pasado a la clara distinción en la que ahora estamos, afortunadamente ${ }^{9}$. Recuérdese, también, cómo la plaga del SIDA modificó no pocos comportamientos, y criminalizó, por ejemplo, las relaciones homosexuales. En todo caso, la defensa del niño como tal niño, los derechos del niño, en tanto que niño, sufrieron un acelerón importante en las Convenciones, Declaraciones, Informes, etc., sobre la infancia y los menores y, a partir de un momento, de forma particular en los abusos de orden sexual por parte de los adultos, que acabaron siendo fuertemente proscritas.

Verdrager $(2013,151)$ apunta, que parafraseo y completo con mis propias reflexiones, cómo el detalle de los derechos y protecciones del niño no serán los mismos en las diferentes Convenciones de derechos del niño a lo largo del siglo Xx. Incluso algunos provienen del siglo XIX, centrados en el trabajo de los niños y menores en la industria, a consecuencia de la revolución industrial y el éxodo de gran parte de la población rural a los extra-radios de las grandes ciudades, fenómeno que todavía es visible en muchas partes del planeta ${ }^{10}$.

9 Verdrager $(2013,139)$ apunta cómo el cardenal Bertone en 2010 trató de asimilar la homosexualidad a la pedofilia, pese a que Benedicto XVI, el año 2008, en un vuelo a los EE.UU., entrevistado por los periodistas, ya había manifestado que homosexualidad y pedofilia eran dos cosas distintas. Más cerca en el tiempo, leo en una información de Aciprensa del 22 de enero de 2018, que el P. Carlos Rosell, teólogo y ex rector del Seminario Santo Toribio de Mogrovejo de la Arquidiócesis de Lima (Perú), aseguró que "todos los casos que ha habido de pedofilia" en la Iglesia se deben "a comportamientos homosexuales". Me pregunto con qué pruebas lanzó tal afirmación que, en la actualidad, prácticamente nadie defiende.

10 Permítaseme aquí un breve apunte personal. Hace años, unos doce más o menos, con un grupo de amigos participé en una visita guiada a las minas de Gallarta en Bizkaia, así como a su Museo Minero. Tengo fotocopia de un certificado de defunción por un accidente en la mina, de un menor de 9 años de edad el año 1887. Transcribo lo que consigo leer de la fotocopia del Acta: "En San Salvador del Valle, a las cuatro de la tarde del seis de noviembre de 1887, ante D. Martín del Valle, juez municipal compareció (nombre difícil de leer) estado civil casado, ocupación empleado, manifestando en calidad de alguacil de este Concejo, que D. (nombre difícil de leer) natural de (difícil de leer), edad nueve años, ocupación jornalero y domiciliado en este Concejo, falleció a las once de la mañana del día cuatro, en el primer nivel de la mina Paquita, a consecuencia de ser cogido por un vagón". Añaden que en la página web del Museo hay una foto de un grupo de mineros en los que se ven niños. Muestra, sin duda alguna, lo que, dicho en nuestro lenguaje y con los valores de hoy, cabe calificar como explotación laboral de la infancia. Aun hoy se me encoge el corazón. 
Verdrager muestra varios textos de Declaraciones, Convenios, etc., no solamente franceses, de las dos primeras décadas del siglo XX, en los que habla de las condiciones del trabajo de niños y menores en la industria, del trabajo nocturno en los niños, sobre la edad mínima requerida para poder acceder al trabajo laboral, también en la agricultura, etc. Señala la Declaración de los derechos de la infancia de la ONU, del año 1959, donde "no había referencia alguna a los abusos sexuales" que, sin embargo, se encontrará el año 1989, reténgase la fecha, en la "Convención internacional relativa a los derechos de la infancia", en cuyo articulado (arts. 19 y 34) la "violencia sexual" es mencionada. Se menciona también cómo el Consejo de la Unión Europea, en el año 2003, adopta la decisión-marco relativa a la explotación sexual de los niños en la Unión Europea. Y continúa Verdrager escribiendo que "en el periodo reciente, la legislación anti-pedófila no ha cesado en su reforzamiento, aun cuando el término pedofilia esté ausente del código penal francés. (...) Algunos han solicitado que la pedofilia, juzgada a veces como la «peor de las perversiones, el mayor atentado a la dignidad humana» ${ }^{11}$, sea considerada como un crimen contra la humanidad; otros han reclamado la prisión perpetua, el enclaustramiento en campos de internamiento, la castración quirúrgica o medicinal (anti-andrógenos), o el restablecimiento de la pena de muerte" (Verdrager 2013, 151).

Al lector informado no le costará encontrar valoraciones similares en la literatura en lengua española. En los lenguajes en los ámbitos familiares o de proximidad, luego más allá de lo "políticamente correcto", estos últimos años, los epítetos para juzgar el abuso sexual en menores se sitúan en el pináculo del horror, como la abominación más rechazable. Además, en la actualidad, es impensable leer en un medio público el menor atisbo de legitimación, justificación o minusvaloración del comportamiento pederasta, tal y como sucedía en determinados ámbitos, hace no más de treinta años, en Europa, como lo hemos comprobado en el caso de Francia, Alemania, Austria y los Estados Unidos ${ }^{12}$.

11 Cita aquí Verdrager (2013) el trabajo de Homayra Sellier (2003, 12).

12 Ruego se me perdone que, por mera comodidad intelectual, me limite a referir, a pie de página, varias entradas en Religión Digital de la mañana del día en el que formulé la primera redacción del texto: "Laicas y laicos de Concepción (en Chile) exigen que se sancione 'con toda la fuerza de la ley' los abusos a menores"; "La Fiscalía pide para el líder del grupo de los 'Miguelianos', Miguel Rosendo, 66 años de cárcel, acusado, entre otras cosas, de tres delitos contra la libertad sexual —uno de agresión sexual continuado y dos de abuso sexual continuado-; "El Instituto de Diálogo Interreligioso (IDI) de Argentina, dirigida por un rabino, un musulmán y un sacerdote católico, se suma a la 
Antes de cerrar este trabajo, quiero detenerme un momento en la cuestión en la que se considera a una persona menor de edad, y en su capacidad de decisión, luego de responsabilidad.

\section{La complicada determinación de la edad legal de los menores}

En un primer momento comentaré una carta firmada por 60 personalidades francesas y publicada el año 1977. Después mostraré la evolución en Francia de la edad de consentimiento sexual en menores en Francia y, a continuación, la legalidad en la edad en menores en España, en diferentes aspectos de su vida, en el año 2018.

\subsection{Sobre un Carta firmada por 60 personalidades francesas y que publicó Le Monde (como remitido) el 26 de enero de 1977}

En enero de 1977, con motivo de abrirse un juicio en un Tribunal francés (Cour d'assisses des Ivelines) sobre tres hombres acusados de atentados contra el pudor sin violencia sobre tres menores en 1973, y que llevaban tres años de detención provisional, un colectivo de 60 personas $^{13}$ redactó un comunicado. En él se señalaba que "una detención provisional tan prolongada les resultaba escandalosa"; que (los acusados) "se arriesgaban a una grave pena de reclusión criminal, sea por haber mantenido relaciones sexuales con menores, chicos y chicas, sea por haber favorecido y fotografiado sus juegos sexuales (jeux sexuels)". Y precisaban en su comunicado que las relaciones

defensa de Francisco tras la carta del ex nuncio en Washington Carlo María Viganò que reclamó la renuncia de Francisco"; "Sus declaraciones en el vuelo de vuelta de Irlanda son tremendamente ofensivas". "Daniel y otras tres víctimas de los 'Romanones', al Papa: "La Iglesia defrauda a las víctimas para abrazar a los abusadores»"; "Los obispos franceses, 'tristes y avergonzados' por los 'atroces' abusos a menores". "Prometen una 'vigilancia implacable y un cambio permanente de actitud' ante la pederastia"; "Los obispos de EE.UU. comparten con el Papa el dolor por 'el demonio del abuso sexual'." "Roma acepta la renuncia del obispo de Wheeling-Charleston, acusado de abusos, y ordena una investigación"; "Julián Barrio (arzobispo de Santiago de Compostela) agradece a Francisco su 'valentía evangélica'. Le da las gracias por su «dolor, humildad y realismo» frente a los abusos. Invita a sus fieles a estar atentos «a cualquier señal que Pedro pueda hacernos para ayudarle»".

13 De los 60 firmantes señalo aquí estos nombres, por ser, quizá, más conocidos en España: Louis Aragon, Roland Barthes, Simone de Beauvoir, Patrice Chéreau, Gilles et Fanny Deleuze, Jean-Pierre Faye, André Glucksmann, Guy Hocquenghem, docteur Bernard Kouchner, Jack Lang, Jean-François Lyotard, Jean-Paul Sartre y Philippe Sollers. 
sexuales fueron sin violencia y consentidas, como manifestaron los menores al juez de instrucción, "aunque la justicia les deniega actualmente todo derecho al consentimiento".

Añaden que "la ley francesa se contradice cuando reconoce capacidad de discernimiento a un menor de trece o catorce años al que puede juzgar y condenar, mientras que esa ley le niega esta capacidad en lo que se refiere a su vida emocional y sexual". Y concluyen su comunicado con estas palabras: "Tres años de prisión por abrazos y besos, es suficiente, no entenderíamos que el 29 de enero Dejager, Gallien y Burckhardt (los mayores acusados) no reencuentren la libertad".

Desconozco cuál fue el veredicto del Tribunal, pero tampoco creo que sea aquí lo esencial. De este comunicado, resaltaría, de entrada, estas ideas: por un lado, una ley que en nada favorece la pedofilia, luego no se pierda de vista que la pedofilia era legalmente perseguida en Francia; que la ley, restrictiva a la hora de conceder valor al consentimiento sexual en menores, suscitó en su momento una viva reacción contraria entre personalidades de primera fila que conformaban parte del diálogo socio-cultural en Francia en la década posterior a mayo del 68. Dicho en otras palabras: la pedofilia, con su paso al acto (sin violencia y con consentimiento de los menores) era aceptada por una parte, significativamente importante, de la población intelectual francesa.

Nótese que el argumento esgrimido reside en la capacidad de consentimiento de los menores, pero, más que eso, y más importante a mi juicio, nótese que nada en el comunicado hace pensar en una condena penal, tampoco moral, de las relaciones sexuales entre adultos y menores, siempre que se hayan llevado a cabo sin violencia y con consentimiento, repito. Estamos muy lejos de la valoración que en la actualidad podemos leer en la prensa de tales relaciones sexuales. Comprender este cambio de actitud social, de los valores como criterios de acción social, comprender tal cambio radical en los derechos del menor, con su consiguiente plasmación en la legislación, conforma una de las razones principales que me animan a reflexionar sobre este tema, del que estamos muy lejos de haber llegado a su final.

\subsection{La evolución de la mayoría sexual en Francia}

Traslado aquí, brevísimamente, la evolución de la edad en la que se considera mayoría sexual en Francia (Verdrager 2013, 62-63). En 
tiempos de Napoleón III (ley de 1863) la mayoría sexual se fijó en los 13 años de edad. En 1942, el gobierno de Vichy del mariscal Pétain, mantuvo los 13 años para las relaciones sexuales heterosexuales y fijó en 21 años la mayoría de edad en las relaciones homosexuales, coincidiendo con la edad de mayoría civil. Tres años después, una ordenanza del General De Gaulle sube la mayoría sexual heterosexual a los 15 años, manteniendo la de la relación homosexual a los 21 años. El año 1974, en la presidencia de Giscard d'Estaing, además de descender la edad civil de los 21 a los 18 años de edad, se mantiene la mayoría sexual heterosexual en los 15 años y se rebaja la homosexual a los 18 años de edad. En fin, al poco de acceder al poder Mitterrand, el año 1982, se establece la mayoría de edad sexual, tanto para las relaciones heterosexuales como para las homosexuales, a los 15 años de edad.

\subsection{Las edades legales de los menores en España en el año 2018}

Veamos ahora en un apunte breve cuáles son las edades legales en España, en los menores, según en qué conceptos, en el año 2018.

Los menores pueden trabajar a partir de los 16 años, según el Estatuto de los Trabajadores. Aunque no pueden ejercer trabajos nocturnos, realizar horas extras ni ocupar ciertos puestos en virtud de la seguridad laboral. Con el trabajo viene la obligación de pagar impuestos sobre la renta.

La edad legal para contraer matrimonio en España es de 16 años, aunque es preciso que la persona esté emancipada. También pueden mantener relaciones sexuales consentidas a partir de esa edad (hasta el año 2015, era de 13 años). Al mismo tiempo, las mujeres de 16 o 17 años necesitan un permiso de los progenitores para interrumpir un embarazo no deseado.

El Código Penal es específico para los menores. Este código distingue entre menores de 14 y 15 años por un lado y de 16 y 17 años por otro. La ley establece, entre otros, límites a los años de reclusión o centros específicos de internamiento, en razón, además de la gravedad del delito, de la edad del menor.

Los pacientes de 16 años pueden tomar sus propias decisiones en materia médica, salvo incapacidad judicial, intelectual o emocional.

Con 15 años pueden sacarse el carné de conducir para un ciclomotor y con 16 años para una motocicleta de hasta 125 CC. Además, con 16 años se puede obtener una autorización especial de uso de armas, aunque con limitaciones. 
Sin embargo, no pueden votar hasta los 18 años. Tampoco se les puede expender tabaco o bebidas alcohólicas (ni beberlas en público) hasta cumplir 18 años, edad en la que adquieren la mayoría civil.

Quiero añadir, expresamente, que estos datos ya los he mostrado, ajustados al momento, en Comisiones en el Senado como en el Parlamento español a las que fui invitado, así como en muchos congresos y conferencias, también en los locales del Plan Nacional contra las drogas. He referido que, sabiendo que la inmensa mayoría de jóvenes con 16 y más años ya bebían alcohol, en público, nos encontrábamos con, probablemente, la ley y normativas más incumplidas en España. Pedí, reiteradamente, un debate sobre la edad y sus limitaciones legales en los jóvenes. Solo conseguí que me acusaran de querer fomentar el consumo de alcohol en menores de 18 años.

\section{Conclusiones: del padre rey, al niño rey}

Sostengo, con otros muchos investigadores, que hubo en los años 60 una auténtica revolución cultural tanto en EE.UU. como en Europa. Respecto de España, sigo a José Vidal-Beneyto cuando afirma, refiriéndose a las décadas de los años 60 y 70 del siglo pasado que, "en efecto, en esas dos décadas, sobre todo en la primera, es cuando tiene lugar la gran mutación española, cuando se opera la metamorfosis total de España"14. Así fue, en efecto, en múltiples campos. Por lo que concierne a este texto apuntemos los cambios en el campo de la sexualidad, en el de la familia, en las relaciones hombre-mujer y en sus relaciones sexuales (que ahora se vive con el caso del tenor Plácido Domingo en todo el mundo, aunque con reacciones diferentes en los grandes festivales musicales norteamericanos y europeos), en el papel de la mujer en el trabajo, en el ocio, en la familia, en las nuevas relaciones con el cuerpo, en la secularización, etc., aunque, insisto, ello no supuso una generalización de la aceptación de la relaciones sexuales con menores, salvo en ciertos ámbitos y por un periodo relativamente reducido de tiempo.

Pero añado que, tampoco en el conjunto de la sociedad, se le concedió la importancia que se le otorga en la actualidad. Es lo que intento mostrar y analizar en mi texto: cómo se ha transitado

14 José Vidal-Beneyto (2006). "Una década prodigiosa: los años 60 entre reformas y rupturas", discurso de investidura de Doctor Honoris Causa de la Universidad de Valencia. 
de un rechazo, aunque generalizado, de mediana intensidad, de tales relaciones (con la excepción de cierta intelligentsia, con fuerte presencia mediática, que las aceptaba y promovía), hasta la actualidad, en la que aparece como el más horrendo de los delitos, el escándalo supremo, junto a las agresiones violentas contra las mujeres.

Siguiendo el razonamiento de algunos analistas, cabe hablar que entre los años finales de los 60 y 70 del siglo pasado, hasta nuestros días, se ha vivido un choque entre dos paradigmas (que en al caso de la pederastia del clero, han denominado también dos sacralidades): uno menguante y otro creciente. El paradigma menguante es el del padre y el creciente el del hijo. Hemos transitado del padre rey al niño rey. Este cambio paradigmático es particularmente cierto en la sociedad de matriz católica, a tenor del modelo de familia patriarcal en él dominante.

¿Qué había pasado? Pues que asistíamos al derrumbe que tenía lugar en la familia tradicional, de matriz mediterránea, romana y católica, amén de protectora de todos (hasta los fámulos, de ahí la denominación familia) hacia otro modelo de familia, liberal, de matriz protestante o "sin religión", e individualista, donde ahora, muy mayoritariamente, estamos en el mundo occidental.

De ahí que hayamos transitado de una familia patriarcal, centrada en el mundo rural en el abuelo, en la sociedad moderna en el padre (siempre hombres), a una familia centrada sea en los progenitores (vistos como complemento psicológico, como prótesis individualista, según Lipovetsky), sea en los niños, a veces cuando falla la relación de pareja o para ¡cruel paradoja! en un postrer intento para salvarla. Así el niño se convierte (se puede convertir si las cosas van medianamente bien) en el rey de la familia, destronando completamente al rey de otrora, al padre. Y el rey es inviolable. Sagrado dirán algunos. Antes y ahora. Como escribe Bobineau (2018): "el niño rey es el centro del afecto y la preocupación de la familia, que consume más y más tiempo. Deseado, porque los padres están proyectados en él: se dará cuenta de lo que sus padres no pudieron lograr. Por lo tanto, se volvió intocable, eminentemente valioso, breve, sagrado. Pero su legitimidad no proviene de arriba sino de abajo, de sociedades democráticas individualistas".

Y un rey destronado no puede violar al nuevo rey, de ahí el conflicto de sacralidades, a decir de Bobineau. Añádase a ello, hablando de la pederastia clerical, la lectura que cabe hacer, en la era secular, del comportamiento de un padre, visto como un "padre espiritual" que abusó del niño en la era de la cristiandad, con una Iglesia que pretendía imponer, entre otras cosas, su propia moral. 
Particularmente, obsesivamente, determinada moral sexual, en la que el placer sexual era singularmente objeto de sospecha, a otra era, ya la nuestra, en la que se impone "hacer el amor y no guerra". Lo que tiene su traslado en los comportamientos humanos y en la lectura de los Derechos Humanos consiguientes.

\section{Referencias bibliográficas}

Bach, Gérard. 1984. "Le miroir de nos pratiques", Homophonies, 47, septiembre, 38-39.

Benedicto XVI. 2019. "La Iglesia y el escándalo del abuso sexual", ACl prensa. https://www.aciprensa.com/noticias/el-diagnostico-de-benedicto-xvi-sobrela-iglesia-y-los-abusos-sexuales-35201

Bobineau, Olivier. 2018. "Nous ne sommes qu'au début des révélations d'affaires de pédophilie dans l'Eglise", Le Monde, 25 de septiembre. https://www.lemonde.fr/idees/article/2018/09/25/olivier-bobineau-nousne-sommes-qu-au-debut-des-revelations-d-affaires-de-pedophilie-dans-Ieglise_5359700_3232.html

Cooper, David. 1986. La muerte de la familia, Barcelona: Planeta de Agostini Duvert, Tony. 1974. Le Bon sexe illustré, París: Éditions de Minuit.

Eberstadt, Mary. 2009. "How pedophilia lost its cool", First Things, https:// www. firstthings.com/article/2009/12/how-pedophilia-lost-its-cool

Elzo, Javier. 2019. "Abusos de menores en la Iglesia: ¿Cómo hemos llegado hasta aquí? Breves apuntes sociológicos", Razón y Fe, 1437, enerofebrero, 59-70.

Foucault, Michel. 1978. "La loi de la pudeur", Dits Ecrits III, texto n 263. http://1 libertaire.free.fr/MFoucault317.html

Meotti, Giulio. 2013. "II '68 dei pedofili", II Flogio, 7 de septiembre. Disponible el original en italiano en: http://magister.blogautore.espresso.repubblica. it/2019/04/16/il-\%E2\%80\%9968-dei-pedofili/?refresh_ce. Y traducido al castellano en: https://www.aciprensa.com/noticias/el-68-de-los-pedofilosexperto-da-la-razon-a-benedicto-xvi-sobre-abusos-en-la-iglesia-60427

Rind, B., Tromovitch. P. y Bauserman, R. 1998. "A meta-analytic examination of assumed properties of child sexual abuse using college samples", Psychological Bulletin American Psychological Association, 124(1): 22-53.

Schérer, René. 1982. "René Schérer, philosophe inculpé", Gai Pied Hebdo, 45, 27 noviembre-3 diciembre.

Sellier, Homayra. 2003. Innocence-en-danger.com. Internet: le paradis des pedophiles, París: Plon.

Urra, Javier. 2007. "SOS... Víctima de abusos sexuales", Madrid: Pirámide.

Verdrager, Pierre. 2013. L'enfant interdit: Comment la pédophilie est devenue scandaleuse. París: Armand Colin. 


\section{Copyright}

Deusto Journal of Human Rights / Revista Deusto de Derechos Humanos is an Open Access journal; which means that it is free for full and immediate access, reading, search, download, distribution, and reuse in any medium only for non-commercial purposes and in accordance with any applicable copyright legislation, without prior permission from the copyright holder (University of Deusto) or the author; provided the original work and publication source are properly cited (Issue number, year, pages and DOI if applicable) and any changes to the original are clearly indicated. Any other use of its content in any medium or format, now known or developed in the future, requires prior written permission of the copyright holder.

\section{Derechos de autoría}

Deusto Journal of Human Rights / Revista Deusto de Derechos Humanos es una revista de Acceso Abierto; lo que significa que es de libre acceso en su integridad inmediatamente después de la publicación de cada número. Se permite su lectura, la búsqueda, descarga, distribución y reutilización en cualquier tipo de soporte sólo para fines no comerciales y según lo previsto por la ley; sin la previa autorización de la Editorial (Universidad de Deusto) o la persona autora, siempre que la obra original sea debidamente citada (número, año, páginas y DOI si procede) y cualquier cambio en el original esté claramente indicado. Cualquier otro uso de su contenido en cualquier medio o formato, ahora conocido o desarrollado en el futuro, requiere el permiso previo por escrito de la persona titular de los derechos de autoría. 